\title{
Numerical simulation of rainfall tests on small-scale slope model
}

\author{
Fakher Hamrouni ${ }^{1, a}$, Houcem Trabelsi ${ }^{1}$ and Mehrez Jamei ${ }^{1}$ \\ ${ }^{1}$ National Engineering School of Tunis, Civil Engineering Department, Tunis El Manar University, Tunisia
}

\begin{abstract}
Rainfall-induced landslides are becoming ever more frequent in many regions in the world. In general, the slope failures occur during or immediately after the rainfall. In Tunisia, several regions are concerned by deep or shallow landslides induced by rainwater infiltration, particular in Beja (Tibar). However, due to the high cost of field tests, the quantification of rainwater effects still not adequately clarified. Different small scale slope models were used to study landslide as a result of change in saturation degree. In this paper, we present numerical simulation of rainfall tests on small scale model used clayey soil from a landslide site in Beja, Tibar. The aim of this paper is to study landslide in small scale clayey slope used the same characteristics and conditions of the experimental model realised by Rolando et al. (2004). For this simulation, we will use the numerical approach used to simulate rainfall tests already developed by Rolando et al. (2004). Numerical simulation is conducted using CODE-BRIGHT software.
\end{abstract}

\section{Introduction}

Numerous research studies have been conducted to investigate infiltration of rainwater into a slope and the effect of water infiltration on slope stability. The studies show that the increase of pore-water pressure (increase of water table level) is described as a mainly condition leading to slope failure. In addition, the increase of moisture content decreases the shearing resistance of soils. Indeed, until now there are difficulties to explain several cases of landslides induced by rainfall. In order to study the landslide as a result of change in saturation degree, and to clarify the rainwater infiltration effects, different small scale models slopes were used. The physical laboratory model with reduced dimensions has many advantages, like the identification of failure mechanisms, failure initiation and slope movements. In this part, we will present results of numerical simulation of rainfall test on small scale clayey slope model. Based on the assumption of effective stress, a simply modified Mohr-Coulomb model taking into account the suction has been used. The proposed model takes into account the reduction of cohesion under humidification.

\section{Model properties}

The numerical models chosen, like Mohr-Coulomb model used to simulate the failure plane in the small scale model, the Van Genuchten model for the retention curve, and Kozeny's model for the intrinsic permeability, help us to make a numerical simulation of a rainfall test on small scale already developed by Rolando et al (2004) that describe perfectly the experimental slope behaviour. The computed results obtained are similar to the

\footnotetext{
a Corresponding author: fakher.hamrouni@gmail.com
}

experimental results. In the present paper, the objective is to study landslide in the clayey soil by numerical simulation of a rainfall test on reduced model using the same geometric characteristics, initial conditions and boundary conditions of the physical model used in the tests realised by Rolando et al (2004), only the soil used to construct the experimental slope is changed with the fact that the similitude conditions are not discussed in this paper (see Hamrouni et al., 2016).

Table 1. Geometric characteristics of the reduced model

\begin{tabular}{|c|c|}
\hline Side & $(\mathbf{m m})$ \\
\hline Length & 1970 \\
\hline Width & 800 \\
\hline height & 900 \\
\hline
\end{tabular}

The soil properties as shown in Table 2, this soil provided from a landslide site in Beja, (Tibar) Tunisa. 
Table 2. Properties of the clay soil

\begin{tabular}{|c|c|}
\hline Parameter & Value \\
\hline Permeability at saturation $\mathrm{k}(\mathrm{m} / \mathrm{s})$ & $10^{-7}$ \\
\hline Intrinsic Permeability at saturation $\mathrm{K}\left(\mathrm{m}^{2}\right)$ & $10^{-14}$ \\
\hline Specific gravity $\left(\mathrm{gr} / \mathrm{cm}^{3}\right)$ & 2.63 \\
\hline Effective friction angle $\left({ }^{\circ}\right)$ & 10 \\
\hline Effective cohesion $(\mathrm{KPa})$ & 4 \\
\hline Plasticity index (\%) & 32 \\
\hline Liquid limit (\%) & 64 \\
\hline
\end{tabular}

The experimental slope made of homogeneous layer of soil with thickness $\mathrm{h}=30 \mathrm{~cm}$ that was constructed over an impermeable base, the reduced slope is constructed under an initial water content $\mathrm{w}=10 \%$. Figure 1 shows the details of the reduced model.

We will retain the same conditions for the clayey slope.

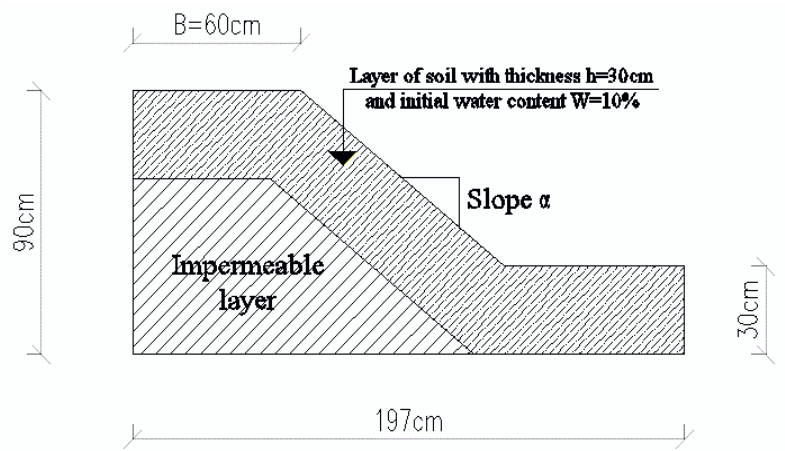

Figure 1. Details of the reduced model used

Hydraulic properties of the marly clay (water retention curve, permeability function, and intrinsic permeability) were investigated.

\subsection{Retention curve}

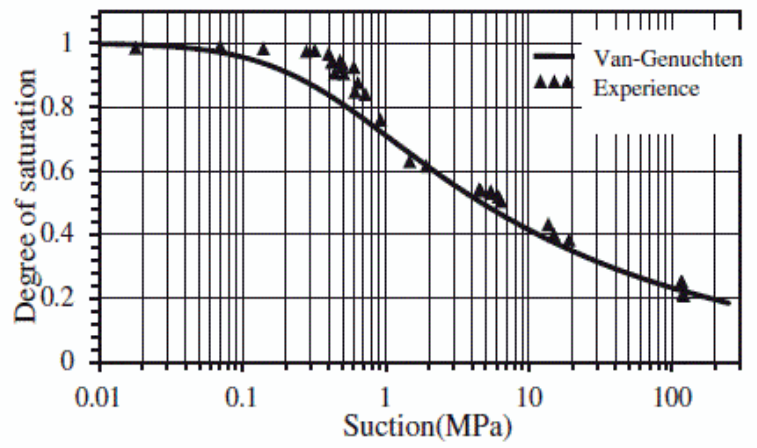

Figure 2. Water retention curve of the clay from Beja area

For the retention curve model, the Van-Genuchten model (1980) equation was calibrated on this experimental data as following:

$$
S_{e}=\frac{S_{l}-S_{r l}}{S_{l s}-S_{r l}}=\left(1+\left(\frac{u_{g}-u_{w}}{P}\right)^{\frac{1}{1-\lambda}}\right)^{-\lambda} ; \lambda=0.2 ; p=0.1 \mathrm{MPa}
$$

This equation contains the parameters $\lambda$ and P. The first $(\lambda)$ essentially controls the shape of the curve while the second $(\mathrm{P})$ controls its height.

\subsection{Intrinsic permeability}

The permeability at saturation of this marly clay is $\mathrm{K}=10^{-7} \mathrm{~m} / \mathrm{s}$, the intrinsic permeability $\mathrm{k}=10^{-14} \mathrm{~m}^{2}$.

A simple function of the type of medium and its porosity is usually used like Kozeny's formula:

$$
\mathrm{k}=\mathrm{k}_{o} \frac{\varphi^{3}}{(1-\varphi)^{2}} \frac{\left(1-\varphi_{o}\right)^{2}}{\varphi_{o}^{3}}, \mathrm{k}_{o}=10^{-14} m^{2}
$$

Where $\varphi_{0}$ is the reference porosity and $\mathrm{k}_{0}$ is the intrinsic permeability at the reference porosity.

\subsection{Relative permeability}

The function for calculating liquid relative permeability is a generalized power function of degree of saturation:

$$
k_{r l}=A S_{e}^{\lambda}
$$

This power function is independent of the retention curve assumed.

\subsection{Mechanical model}

In this case, we used the Mohr-Coulomb model to simulate the failure slope in the scale model. This model assumes that the state of stress of unsaturated soils is defined by two independent variables: the net stress and the suction as stress acting on the mechanical parameters, which are used to explain the unsaturated soil behaviour. In this model the relationship between cohesion and suction is simulated as a linear function. The proposed model is written in the context of the elasticViscoplasticity.

\subsubsection{Elasticity}

Linear elasticity with parameters $\mathrm{E}$ and $v, \mathrm{E}$ is the Young modulus and $v$ is the poisson's ratio. For the clay soilt $\mathrm{E}=44.52 \mathrm{MPa}$ and $v=0.3$.

\subsubsection{Viscoplasticity}

The viscoplastic constitutive model:

$$
\frac{d \varepsilon^{p}}{d t}=\Gamma\langle\Phi(F)\rangle \frac{\partial G}{\partial \sigma}
$$


Where $\Gamma$ is the viscosity, $F$ is the yield function, $G$ is the plastic potential ( in this case $F=G$ ), $\Phi$ is the stress function and $\varepsilon^{\mathrm{p}}$ is the plastic deformation.

The total deformation $\varepsilon$ is defined by the following expression:

$$
\frac{d \varepsilon}{d t}=\frac{d \varepsilon^{e}}{d t}+\frac{d \varepsilon^{p}}{d t}
$$

The expression of the stress function:

$$
\Phi(F)=F^{m}
$$

The yield function $F$ is defined by the following expression:

$$
F=q-\delta p^{\prime}-c \beta
$$

Where $\mathrm{q}$ is the deviatoric stress, $\mathrm{c}$ is the cohesion, $\mathrm{m}$ is a parameter which depends on the material, $\delta$ and $\beta$ are defined by the following expression:

$$
\delta=M=\frac{6 \sin \phi^{\prime}}{3-\sin \phi^{\prime}}=0.4 \quad \beta=\frac{6 \cos \phi^{\prime}}{3-\sin \phi^{\prime}}=2.1
$$

Where $\phi^{\prime}$ is the friction angle, invariants used in the models are defined as:

$$
\begin{aligned}
& p=\sigma_{o c t}=\frac{1}{3} I_{1}=\frac{1}{3}\left(\sigma_{x}+\sigma_{y}+\sigma_{z}\right) \\
& q=\frac{3}{\sqrt{2}} \tau_{o c t}=\frac{1}{\sqrt{2}} \sqrt{\left(\sigma_{x}-\sigma_{y}\right)^{2}+\left(\sigma_{y}-\sigma_{z}\right)^{2}+\left(\sigma_{z}-\sigma_{x}\right)^{2}+6\left(\tau_{x y}^{2}+\tau_{y z}^{2}+\tau_{z x}^{2}\right)}
\end{aligned}
$$

\section{Numerical simulation programs}

A finite element (FE) analysis was carried to analyse the scale model tests. The numerical program is outlined in Table 3 .

In the numerical modelling, the effect of temperature is not taken into account (isothermal conditions).

Table 3. Numerical program.

\begin{tabular}{|c|c|c|c|}
\hline $\begin{array}{c}\text { Case } \\
\text { No. }\end{array}$ & $\begin{array}{c}\text { Type of } \\
\text { test }\end{array}$ & Material & Remarks \\
\hline 1 & Rainfall & $\begin{array}{c}\text { Silty } \\
\text { sand }\end{array}$ & $\begin{array}{c}\alpha=40^{\circ}, \mathrm{D}_{\mathrm{r}}=50 \%, \mathrm{~W}=10 \%, \\
\mathrm{~s}=34.5 \mathrm{KPa}, \mathrm{r}=42-72 \mathrm{~mm} / \mathrm{h}, \\
\text { and } \beta^{*}=1\end{array}$ \\
\hline 2 & Rainfall & Clay & $\begin{array}{c}\alpha=40^{\circ}, \mathrm{D}_{\mathrm{r}}=50 \%, \mathrm{~W}=10 \%, \\
\mathrm{~s}=51.402 \mathrm{MPa}, \mathrm{r}=42-72 \\
\mathrm{~mm} / \mathrm{h}, \text { and } \beta^{*}=0.7\end{array}$ \\
\hline
\end{tabular}

$\beta^{*}$ is the percentage of rain that infiltrates into the soil.

\subsection{The obtained results}

The numerical simulation of test 1 have been achieved, the idea was to simulate a rainfall test on small-scale model already developed by Rolando et al. 2004, in order to validate the proposed numerical models chosen. The numerical results are similar to the experimental results. The numerical model proposed perfectly describes the behavior of the experimental slope model.

The main experimental and numerical results of test 1 (sandy slope),

- Test results showed that the slope failure was induced when the soil moisture content near the toe of the slope reached nearly full saturation.

- The failure process in terms of the "localized" plastic deformation, involved only the superficial portion of the slope (shallow landslide).

- The development of water table near the toe of the slope and the wetting front also moved upward, causing an increase in the volumetric water content near the surface soil at the slope toe.

The increase of the pore-water pressure due to the increase of water table level in the region near the toe of the slope is described as a mainly condition leading to slope failure in this case (for the sandy slope). The high permeability of this silty sand $\left(\mathrm{K}=1.810^{-4} \mathrm{~m} / \mathrm{s}\right)$ increase the rate of infiltration of the rainwater into the slope and increase the saturation degree in the slope which will lead to the decrease of the cohesion (apparent cohesion) and the decrease of the shear strength of the soil.

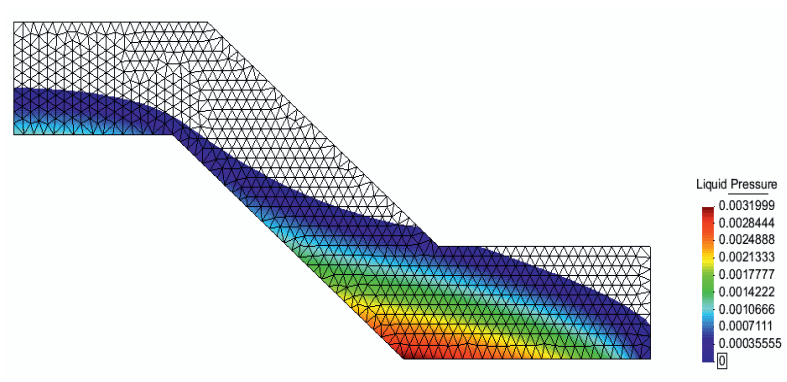

Figure 3. Numerical result of distribution of saturated zone at the time of failure (silty sand) 


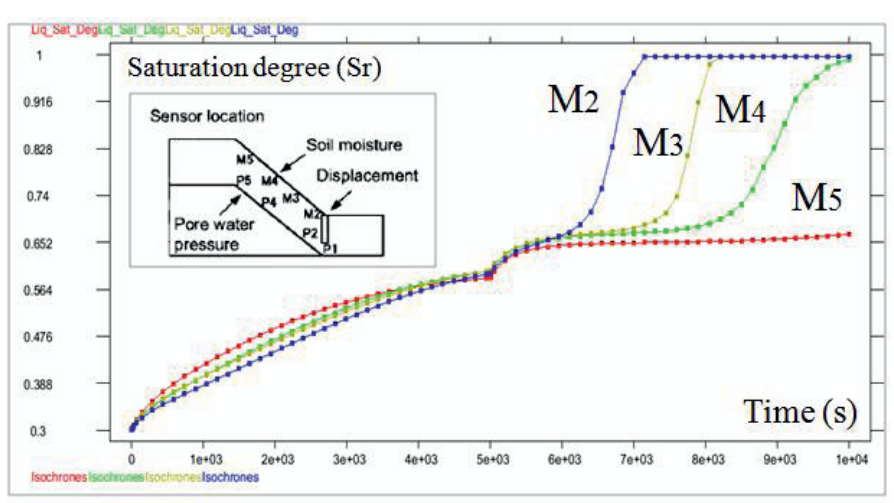

Figure 4. Time histories of saturation degree

In this paper, we will present numerical results of the rainfall test used the same model characteristics of the case 1 (reference case), the only difference is the material used to construct the slope (clay soil). This is in order to study the landslide in clayey soil, induced by rainfall. The main objective is to clarify the main parameters that cause landslide in this lower permeable soil.

\subsection{Numerical simulation of test 2}

The average size of the finite element mesh chosen for the simulation was $0.028 \mathrm{~m}$ and the number of triangular elements was 1839. The simulations are done according to the two following assumptions: small deformation and plane strain condition.

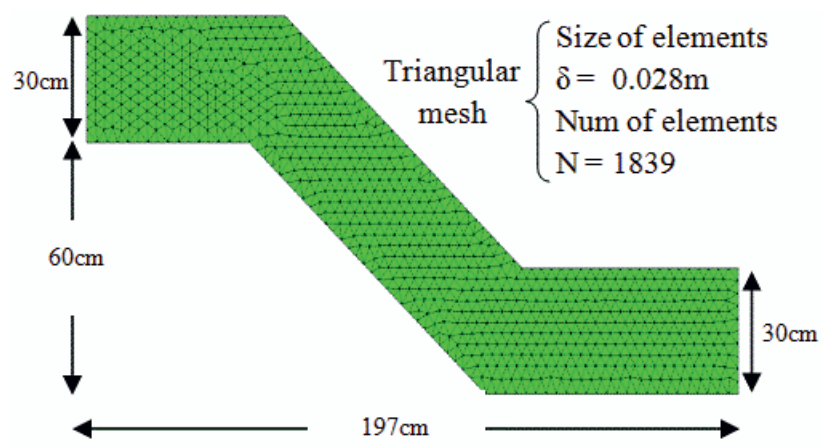

Figure 5. Mesh elements chosen for the simulation

\section{Numerical results of rainfall test $n^{\circ} 2$}

The boundary conditions and numerical modelling procedures adopted are identical to those used in the test 1 (reference case). In this part, we will present results of numerical simulation of failure initiation in a reduced model of a clayey slope.

Numerical results: the time required for the slope failure in case 2 (clayey slope) was longer than in case 1 (silty sand) because of low permeability and the strong cohesion of the clay $\left(c^{\prime}=4 \mathrm{KPa}\right)$.

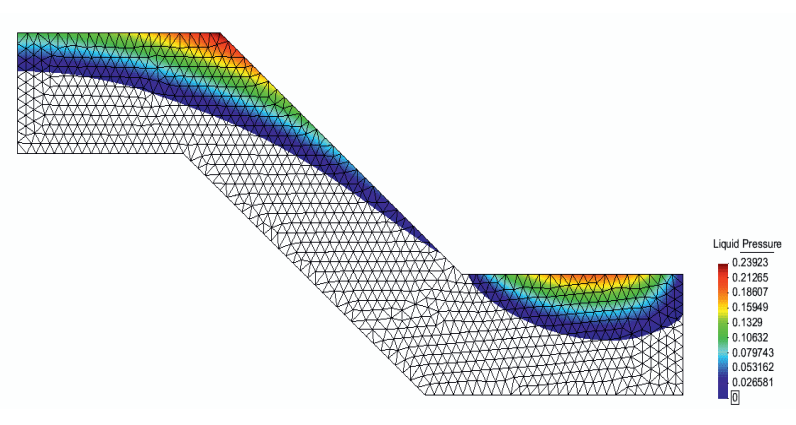

Figure 6. Numerical result of distribution of saturated zone at the time of failure (clay soil)

The low permeability of clay soil $\left(\mathrm{K}=10^{-14} \mathrm{~m}^{2}\right)$ does not allow rainwater to seep into the slope. The numerical results show that the water accumulates in the superficial layer with an increase of pore-water pressure in this region.

In this case, the decrease of cohesion and effective stress due to the increase of pore-water pressure $\left(\mathrm{u}_{\mathrm{w}}=0.32 \mathrm{MPa}\right)$ in the superficial layer is described as a mainly condition leading to slope failure (superficial portion).

Many slope failures occur during or after the rainfall in the Beja region (Tunisia), especially in a plastic clay soil. Stability problems are caused by soil saturation and the presence of cracks which are developed after along dry summer. The presence of cracks in the superficial layer (topsoil) increases the permeability of the clay soil.

In the aim to attain conditions near the real slope conditions, we simulate that the superficial layer $(\mathrm{h}=10 \mathrm{~cm}$ in reduced model) is a permeable layer (case of a cracked layer) by increasing the permeability.

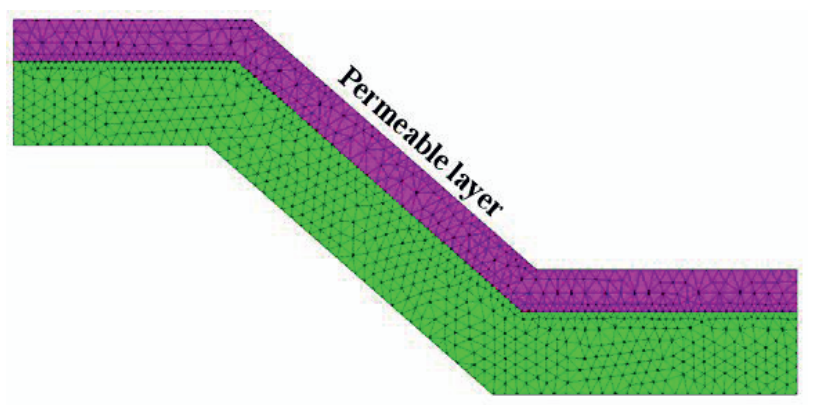

Figure 7. The chosen model for the simulation

In this part, we will study the effect of superficial layer (topsoil) on slope stability; the Table 4 shows the numerical program for this test.

Table 4. Numerical program.

\begin{tabular}{|c|c|c|c|}
\hline $\begin{array}{c}\text { Case } \\
\text { No. }\end{array}$ & $\begin{array}{c}\text { Type of } \\
\text { test }\end{array}$ & Material & Remarks \\
\hline 3 & Rainfall & Clay & $\begin{array}{c}\alpha=40^{\circ}, \mathrm{D}_{\mathrm{r}}=50 \%, \mathrm{~W}=10 \% \text { et } \\
\mathrm{r}=42-72 \mathrm{~mm} / \mathrm{h}, \mathrm{s}=51.402 \mathrm{MPa} \\
\beta^{*}=0.7, \mathrm{~K}_{1}=10^{-11} \text { and } \mathrm{K}_{2}=10^{-14}\end{array}$ \\
\hline
\end{tabular}




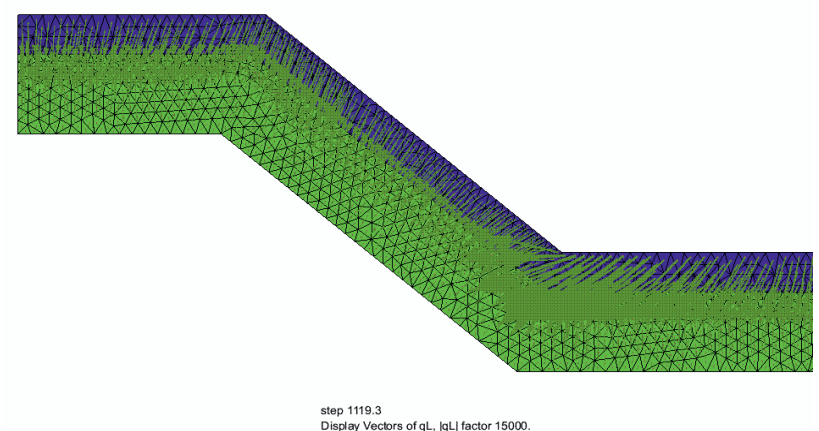

Figure 8 . Water flow vectors at the start of rainfall

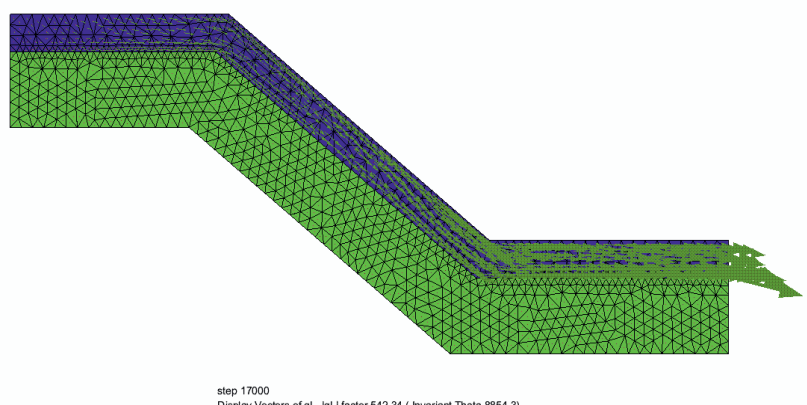

Figure 9. Water flow vectors at the end of rainfall

The clayey layer with low permeability represents an impermeable layer for this small scale slope model. The lowest layer requires a lot of time for it begins saturation. The above figure shows the direction of water flow.

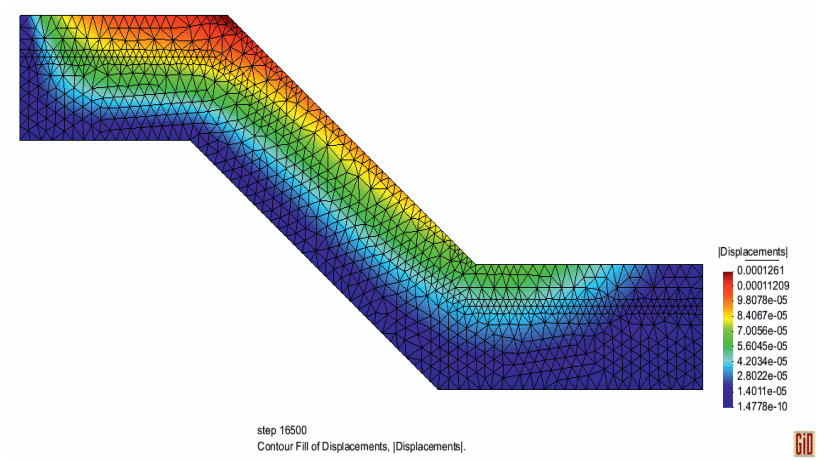

Figure 10. Numerical result of displacement

The failure process involved only the superficial portion of the slope as it's noted above.

\section{Conclusion}

Rainfall test on small scale slope model can help us to find an explanation of the phenomena of rainfall induced landslide especially for the clayey soil. Numerical simulation of the rainfall test on reduced model already developed by Rolando et al (2004), for the case of sandy slope allows us to validate the proposed numerical approach in the first part and to clarify the main parameters that cause landslide induced by rainwater infiltration in the both cases: the sandy slope $\left(\mathrm{c}^{\prime}=0 \mathrm{MPa}\right.$ and $\mathrm{K}=1.810^{-4} \mathrm{~m} / \mathrm{s}$ ) and for a plastic clayey soil, in the second part. In this paper, we have not presented the numerical results of this test (test No 9 R.P.Orense 2004). The validation of the numerical approach was already conducted and published (see Hamrouni et al., 2015). The idea is here to use the numerical approach to simulate landslide in clayey slope using the same geometric characteristics of the reduced model. Some results obtained by numerical simulations of rainfall tests across a clayey soil in the scale model:

- In the case of homogenous sloping (test 2), landslide occur when a water table developed in the superficial portion of the slope and the porewater pressure increases in this region. The increase of water pressure also the saturation degree in this part due to the low permeability of the clay $\left(\mathrm{k}=10^{-14} \mathrm{~m}^{2}\right)$.

- In order to reach conditions near the real slope conditions, we will simulate that the superficial layer is a cracked layer by increasing the permeability (the value is shown according some laboratory odometric tests on fissured clay, see Louati et al., 2015).

- Numerical result of test 3 shows that the development of cracks in the slope increases the permeability of soil and the rainwater infiltration into the slope. So it leads to increase of the moisture content and pore-water pressure in the slope and the decrease of shear strength of soil which leads to the slope failure

\section{References}

1. Rolando P.Orense, Suguru Shimoma, Kengo Maeda and Ikuo Towhata, "Instrumented Model Slope Failure due to Water Seepage, "Journal of Natural Disaster Science, vol. 26,pp. 15-26, 2004

2. Suguru Shimoma, Rolando P.Orense, Tsuyoshi Honda, Kengo Maeda and Ikuo Towhata, “

3. Trabelsi, H, Jamei, M, Zenzri, H, and Olivella, S, (2012). Crack patterns in clayey soils

Experiments and modeling. International Journal for Numerical and Analytical methods in geomechanics, 36(11), 1410-1433.

4. Lyesse Laloui, Mathieu Nuth," On the use of the Generalized effective stress in the constitutive Modeling of unsaturated soils,"Computers and Geotechnics, vol. 36, pp. 20-23, 2009.

5. Chales W. W. Ng, Jian Liu, Rui Chen, and Jie Xu, “ Physical and numerical modeling of an inclined threelayer (silty/gravelly sand/ clay) capillary barrier cover system under extreme rainfall, "waste Management, 2015. 
6. M. Jamei, H. Guiras, and S. olivella," Analyse of slope movement initition induced by rainfall using the Elastoplastic Barcelone Basic Model,” European journal of environnemental and civil Engineering. 2015.

7. Hong-Hu Zhu, Bin Shi, Jun-Fan Yan, Jie Zhang, and Jing Wang,"Investigation of the evolutionary process of a reinforced model slope using a fiber-optic monitoring network,'Engineering, Geology, vol. 186, pp.34-43, 2015.

8. F. Louati, H. Trabelsi, and M. Jamei, "Experimental and Numerical Investigation about Permeability of
Fissured Clay", UNSAT, BATNA, 16-17 November 2015, pp. 161-166.

9. F. Hamrouni, H. Trabelsi, L. El Ghezal, and M. Jamei, "Numerical Simulation of Rainfall Test on Small-Scale model", UNSAT, BATNA, 16-17 November 2015, pp. 138-146.

10. F. Hamrouni, M. Jamei, H. Trabelsi, and L. Elghezal, "Numerical back analysis to optimize the laboratory scale model", Proposed for the $12^{\text {th }}$ International Symposium on landslides, ISL Napoli, Italy, 12-19 June 2016. 